\title{
American Pediatric Society 2011 Presidential Address: Earthquakes, Tectonic Shifts in Graduate Medical Education, and the Role of the APS in Finding Solid Ground
}

\author{
GARY R. FLEISHER
}

\author{
Department of Medicine, Children's Hospital-Boston, Boston, MA 02115
}

$\mathrm{M}$ embers of the American Pediatric Society (APS), colleagues, and friends, this morning I will speak to you briefly about earthquakes, tectonic shifts in graduate medical education, and the role of the APS in finding solid ground. Postgraduate training has experienced two shaky decades, rattled first by regulatory mandates instituted at the state level following the Libby Zion case in New York and then by additional rules promulgated nationally by the Accreditation Council for Graduate Medical Education (ACGME). In this address, I offer a perspective on pediatric training in light of these developments and propose a larger role for the APS in the effort to maximize both the safety of patients and the education of residents and fellows.

Since the early 1980s, I have been a member of the National Disaster Medical Service (NDMS), which has led to my participation in two missions related to major earthquakes that claimed approximately 250,000 lives (1). The first of these earthquakes struck Bam on the day after Christmas in 2003. Shortly after arrival, my disaster team erected a field hospital where over a two-week period we cared for more than 500 patients, including approximately 150 children. Initially, many were earthquake victims, who had sustained head injuries, fractures, or lacerations several days earlier. Subsequently, we managed children with problems not caused directly by the earthquake, such as burns from portable kerosene heaters used to warm the inside of tents occupied by families that lost their homes and respiratory insufficiency from bronchiolitis. Mixed in with these acute conditions were patients with chronic illnesses, such as a boy with thalassemia, who sustained a pathologic fracture after tripping on rubble. Despite the chaos, not unexpectedly childbirth continued uninterrupted, and our team looked after three infants born in our field hospital by Caesarean section.

The second earthquake devastated Port au Prince on January 12, 2010. My colleagues and I arrived in Haiti $48 \mathrm{~h}$ afterward and established a field hospital in the middle of the city. Once again, the initial wave of patients suffered predominantly from neglected

Received June 2, 2011; accepted July 22, 2011.

Correspondence: Gary R. Fleisher, M.D., Children's Hospital-Boston, Department of Medicine, 300 Longwood Avenue, Boston, MA 02115, Phone: (617) 355-5022, Fax: (617) 730-0469; e-mail: gary.fleisher@childrens.harvard.edu

Presented at the 2011 Annual Meeting of the Pediatric Academic Societies, Denver, Colorado.

The authors report no conflicts of interest. soft tissue and bony injuries, particularly fractures of the pelvis and the lower extremities. Dehydration followed closely behind. On this deployment, less common conditions included congestive heart failure in a young woman with rheumatic heart disease, tetanus occurring in a teenage boy with a hand injury, and pneumonia complicating congenital heart disease in a 4-wk-old infant.

From these and other missions, during which we cared for a broad range of patients with few resources, I learned two lessons that I feel relate to the situation we now face with residency and fellowship education. The first of these two lessons is that the solution to one person's problems must not be the source of another person's problems. This need to balance conflicting imperatives and not to cause problems for colleagues was brought home to me clearly in Bam and Port-au-Prince. If the emergency physicians in Bam used our two remaining clinical tents for male and female adult wards, our pediatric contingent would not have had an adequate place to care for children. In Port au Prince, if I had insisted on holding several units of blood for my patient with gastrointestinal bleeding, the orthopedic cases about to start in the operating room could not have gone forward. Consideration of the consequences of one's actions on the mission of the entire team led to a "big picture" perspective and a realization that compromise was essential to achieve the greatest good.

The second lesson learned from these disasters is that training must offer extensive experience and independent decision making. In difficult situations one may need to rely upon instincts acquired through long hours of clinical experience and to be comfortable acting on clinical data. Many of the patients in Bam and Portau-Prince had conditions that clearly fell outside the scope of my everyday practice, but with which I usually had at least some experience during my training.

\section{APPLICATIONS OF LESSONS LEARNED TO RESIDENCY \& FELLOWSHIP TRAINING}

As an application of these two lessons to residency and fellowship training, academic leaders in pediatrics need to be sure that changes in work hours don't compromise education

Abbreviation: ACGME, Accreditation Council for Graduate Medical Education 
and that optimizing education doesn't degrade patient safety. Specifically, Lesson \#1 means that the solution to the dutyhours problem mandated by the ACGME must not be allowed to undermine our efforts as educators. Unfortunately, the current focus on duty hours risks precipitating a decrease in clinical experience, a loss of professionalism, and a new set of concerns about patient safety.

I believe that Lesson \#2, the need to acquire adequate clinical experience and confidence with independent decisionmaking, is equally important whether practicing in an austere environment to provide aid during a disaster or working in a training program to become a pediatrician. While I don't routinely drain a peritonsillar abscess or immobilize a fracture with a cast, I have been called upon to perform these procedures on deployments, and I am fortunate to have a broad clinical experience upon which to draw. The acquisition of competency in clinical medicine requires exposure to large numbers of patients over a prolonged period of time. Our responsibility as educators is to ensure for our trainees an experience that is sufficient based both on evidence and, when the evidence is less than conclusive, on our judgment. Otherwise we risk the situation described recently in the New York Times as related to a psychiatry training program: “... not long ago, a senior resident called me to the emergency room. The patient, who was well known to this resident, was a young woman with borderline personality disorder who had superficially cut her wrists after an argument with her boyfriend .... She never had any serious suicidal intent .... The doctor was just two months shy of completing her residency, and evaluating a patient's risk of harm to self or others is a critical skill that is taught early and often to psychiatric residents. She knew perfectly well that the patient was prone to dramatic gestures, but not to suicide. Why then, was she calling me to ask about such a basic issue? Despite having all the knowledge about risk at her fingertips, she didn't feel confident in her judgment. She is hardly alone ...." (2).

\section{DOES THE PUBLIC OPINION CARE ABOUT DUTY HOURS?}

Although all of us realize that physicians operate in an environment that is heavily regulated, few of us have explored the exact nature of the public concerns, which are reflected anecdotally in articles in the popular press. More quantitative information, however, comes from a survey by Blum and colleagues (3),

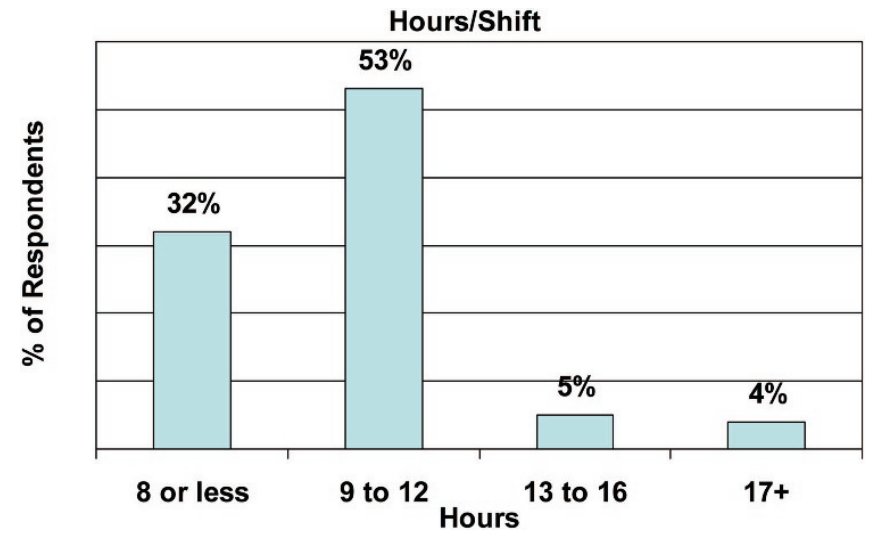

Figure 1. Public opinion about maximum allowable hours/shift for residents. Modified from Blum AB et al. BMC Medicine 8:33, Copyright (C) 2010 Blum et al; licensee BioMed Central Ltd., with permission.

who found that lay respondents favored a maximum shift of 9-12 $\mathrm{h}$ for trainees (Fig. 1). In addition, 80\% indicated that they would want replacement residents if they knew that those caring for them had been working for more than $24 \mathrm{~h}$.

\section{WHAT IS THE EVIDENCE ABOUT THE IMPACT OF SLEEP DEPRIVATION AND DUTY HOURS ON SAFETY AND EDUCATION?}

Regarding the effects of sleep deprivation and changes in duty hours, studies have been performed in the laboratory, in nonmedical settings, and in hospitals. The results of data from these different domains fall into three categories. The first group shows deleterious effects from sleep deprivation among residents at current work levels and improvements with the imposition of restrictions in duty hours; the second group reports deleterious effects and no improvements with the imposition of restrictions at levels enacted several years ago; and the third group describes unintended adverse consequences. I will examine selected reports in each of the three categories and then attempt to weigh the competing lines of evidence to draw reasonable conclusions.

Studies showing a reduction in duty hours improves performance. In a study comparing performance after increases in either hours of wakefulness or blood alcohol level, Dawson and Reid found (Fig. 2) near equivalency between 24-h sleep deprivation and an alcohol level of $0.1 \%$, which defines drunk driving (4). In a nonmedical setting, when compared with their
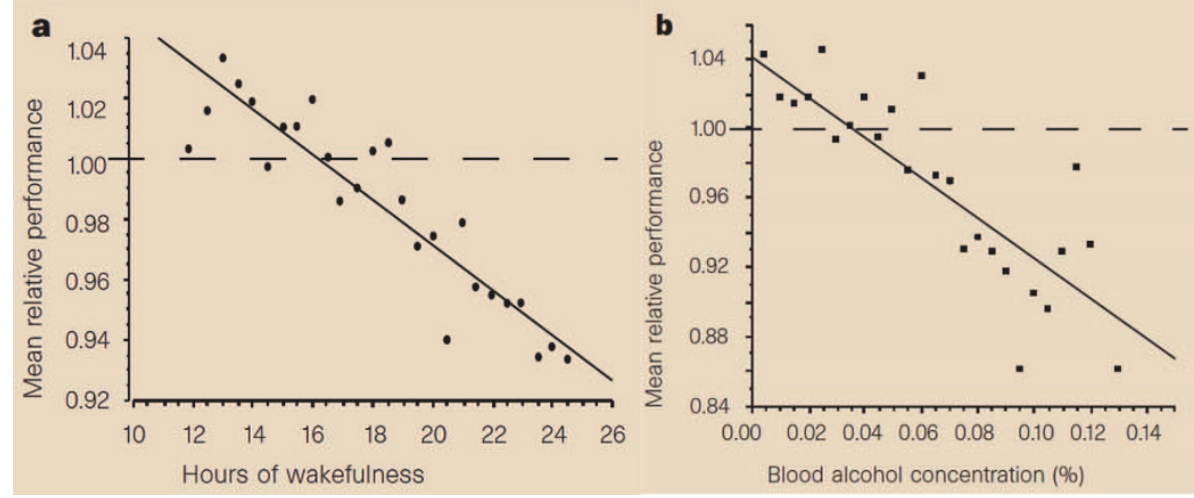

Figure 2. Scatter plot and linear regression of mean relative performance levels against: $a$, time, between the tenth and twenty-sixth hour of sustained wakefulness $(F 1.24=132.9, p<$ $0.05, R 2=0.92)$; and $b$, blood alcohol concentrations up to $0.13 \%(F 1.24=54.4, p<0.05$, $R 2=0.69)$. Reprinted from Dawson $\mathrm{R}$ and Reid K Nature 388:235, Copyright (C) 1997 Nature Publishing Group, with permission. 
first hour of driving, trucker drivers were observed to experience a 15-fold increase in the risk of fatigue-related fatal crashes after driving more than $13 \mathrm{~h}$ (5). In a hospital setting, when compared with interns working an interventional schedule (65 h per week), interns working a traditional schedule ( $85 \mathrm{~h}$ per week) demonstrated significantly more attentional failures by electrooculography, defined by slow rolling eye movements while awake and on duty (6). In a follow up analysis from this study, interns on the traditional rotation schedule made significantly serious medication and serious diagnostic errors (7).

Studies showing a reduction in duty hours results in little or no improvement in performance. In contrast to the studies above, several investigators have found no improvement following a restriction in duty hours, either in selected domains or across a gamut of measures. Laine (8) compared outcomes on a medical ward before and after enactment of legislation following the Libby Zion case, which reduced the duty hours in New York State, and noted no improvement in four different areas (Table 1). Among surgical interns working every second, third or fourth night, Sawyer (9) observed errors rates per shift of $1.1,0.8$ and 0.8 , respectively, with no statistically significant difference. More recently, in 2008 Landrigan conducted a prospective cohort study in three pediatric programs after the introduction of ACGME duty hour standards, and found no change among markers of resident performance, such as the rate of self-reported medical errors, of occupational needle stick exposures, or of both near-miss and actual motor vehicle collisions during the drive home. (Fig. 3) (10).

Studies showing a reduction in duty hours results in unintended adverse consequences. The third group of studies identified potential negative consequences of restricted duty hours including: poor communication, related to less time spent with patients as well as to increased hand-offs; a loss of professionalism secondary to the focus on work hours; and decreases in the acquisition of clinical knowledge and competence. Several investigators have considered the first of these concerns - poor communication and hand-offs. Their findings have included reports of incorrect age and/or gender on written sign-out forms (11) as well as omission of medication allergies for $80 \%$ of patients (12). In an Australian study (13), poor communication at the time of sign-out was judged to constitute the root cause of $11 \%$ of over 25,000 preventable adverse events. On the other side of the coin, limiting hand-offs has been found to reduce both medication errors and length of stay (14).

Regarding worries about a loss of professionalism, trainees themselves have expressed concerns as reflected in the fol-

Table 1. Impact of a reduction in duty hours*

\begin{tabular}{lcccc}
\hline \multicolumn{1}{c}{ Outcome $(\%)$} & $\begin{array}{c}\text { Pre-duty } \\
\text { hours }\end{array}$ & $\begin{array}{c}\text { Post-duty } \\
\text { hours }\end{array}$ & RR & $p$ \\
\hline In-hospital mortality & 9.5 & 9.5 & 1.0 & NS \\
CPR performed & 1.5 & 1.9 & 1.3 & NS \\
ICU transfer & 6.1 & 7.2 & 1.2 & NS \\
Discharge to facility & 7.2 & 6.5 & 0.9 & NS \\
\hline
\end{tabular}

* Reprinted from Laine C et al. JAMA 269:374-378. Copyright (C 1993 American Medical Association, with permission.

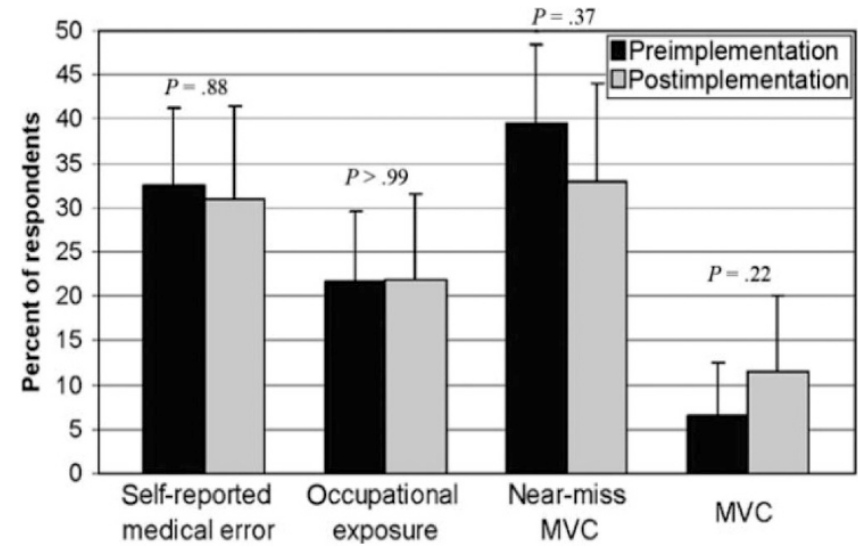

Figure 3. Proportions of residents reporting MVCs, near-miss MVCs, occupational exposures, and medical errors, before (pre) and after (post) implementation of the ACGME duty hour standards. T bars represent $95 \%$ CIs. Repinted from Landrigan CP et al. Pediatrics 122:250-258 (C) 2008 the American Academy of Pediatrics, with permission.

lowing quotation from a resident in a focus group study by Fletcher and colleagues (15): “. . . because they want us to track time in and time out and are really strict about sticking particularly to the 30 -h portion of the rule, the $10 \mathrm{~h}$ between shifts, and I find that affecting care more than anything else because I feel like you can't stay that extra half an hour ....".

Regarding the third concern, the acquisition of clinical knowledge and competence, actual data linking length of training to performance are scant. At the most basic level, residents obviously grow their fund of knowledge over time. Looking at unpublished American Board of Pediatrics intraining exam performance for one program in Boston (Table 2 ), we see a relatively steep climb in scores with progression from internship to senior residency consistently from 2007 to 2009, which speaks not surprisingly in favor of increased knowledge acquisition with greater duration of training (Sectish $\mathrm{T}$, unpublished data). Clinical competence is clearly harder to evaluate than factual learning, but attempts have been made to measure this parameter and to relate it to duration of experience. Using simulation, Essani and colleagues (16) demonstrated that over a period of $8 \mathrm{wk}$ of operating on an anatomical model, surgical residents significantly decreased their operating time from 67 to $37 \mathrm{~min}$ and reduced their anastomotic leak rate from $87 \%$ to $12 \%$. Moving from simulation to the clinical arena, Hutter et al. (17) found a statistically significant decrease in attending physicians' perception of residents' technical skills, clinical judgment and efficiency associated with fewer duty hours. Lastly, in a European hospital (18), after a reduction from 56 to $48 \mathrm{~h}$ per week, most trainees reported that "their educational opportunities had been compromised."

Table 2. ABP in-training examination scores by postgraduate level for residents in three consecutive classes from 2007-2009

\begin{tabular}{cccc}
\hline & PL-1 & PL-2 & PL-3 \\
\hline 2007 & 248 & 360 & 427 \\
2008 & 256 & 361 & 390 \\
2009 & 284 & 363 & 398 \\
\hline
\end{tabular}

* Sectish T (unpublished data). 


\section{CONCLUSIONS}

What conclusions can we reach about the impact of sleep deprivation? Summarizing the data and applying a modicum of common sense, I think we would all agree that prolonged work without sleep, in a setting where residents are making unsupervised decisions, creates both an unsafe environment and a poor educational experience, but that cutting hours too steeply diminishes educational opportunities and actually compromises patient safety. To put the situation in graphic terms and in the interest of finding some common ground among those of us on different sides of these issues in the face of data that are neither complete nor definitive, let's look at some extremes. I suspect that none of us would want a central venous catheter inserted by a resident, who had been awake for $48 \mathrm{~h}$, even if he or she had performed a dozen similar procedures during training, but I doubt that a well-rested senior trainee, who was about to place his or her first line after working for three years at $20 \mathrm{~h}$ per week, would make us feel any safer.

\section{PROPOSAL}

What is my proposal for digging out of the current hole, wherein Congress doubts the willingness of organized medicine to police itself, the ACGME seems focused on the narrow slice of duty hours rather than the whole pie, and many doctors bemoan their inability to influence the national dialogue and waste precious time reminiscing about the days of the giants? I believe we should assemble a broad group of academic pediatric leaders who then start to identify new paradigms for how long and in what fashion we need to train medical school graduates safely to become pediatric practitioners or academic subspecialists. At the same time, we must nurture the excellent research that has begun in this field and expand its breadth to provide more data from which to formulate standards.

To achieve the dual objectives of outstanding patient safety and superb education will require in my opinion a restructuring of residency and of fellowship. I think we will need to make radical changes both in the mechanics and in our thinking, which I have encapsulated in four specific recommendations (Table 3).

First, in regard to the length of training, I recommend carefully reflecting on how much experience has been eliminated by the new regulations and restoring this loss for those planning to practice as general pediatricians or as clinical subspecialists. I suspect that this calculation will show the need for approximately one additional year of training.

My second recommendation is to establish three separate tracks for residency and fellowship training: General Pediatri-

Table 3. Specific recommendations to balance safety and education

1. Extend the length of training to recoup the "lost hours" due to the new rules

2. Establish residency and fellowship tracks to align with the goals of the trainees

3. Create a new requirement for Board eligibility, consisting of a supervised period of practice

4. Add further flexibility to the system cian; Clinical or Clinician-Educator Subspecialist; and Research Subspecialist, the later referring primarily to an individual pursuing a laboratory-based scientific career. Table 4 provides addition detail. Taken together, these tracks will address the issue of the decreased training that results from restricted duty hours, and they will accommodate the needs of residents and fellows pursuing different career paths.

In regard to my third recommendation for a required supervised practice experience, this would include an appointment as a junior attending. It would occur most often in the same institution as the prior training and would provide independent supervisory experiences in clinic during the daytime or covering the inpatient service at night, subject to later review for educational purposes. The additional training in clinic during the daytime would offer, in addition, the opportunity to acquire a new set of advanced skills. Residents, for example, with specific interests might undertake 3-6 mo blocks designed to provide sufficient clinical competence to manage children with common yet complex disorders, such as diabetes or depression, and an emergency medicine fellow might gain advanced skills in bedside ultrasound (19). Keeping in mind the principle that the solution to one person's problems must not be the source of another person's problems, these junior attendings would bill for their services. The revenue generated would both offset hospital expenses and provide the trainees with a supplemental stipend at the level of a junior attending.

Last among my four specific recommendations, I believe that flexibility must be expanded. My recommendation is that governing bodies allow residents to work beyond the prescribed limits in up to $25 \%$ of their shifts, with an average extension of $1 \mathrm{~h}$ and a maximum of $2 \mathrm{~h}$.

\section{ROLE OF THE APS}

I suggest that our society step in to fill what I perceive as a void, namely, lack of sustained input from academic pediatric leadership. The Mission Statement of the APS speaks loudly to this role by emphasizing education along with research. That the APS, in collaboration with the other pediatric societies, hosts the appropriate membership for this task is re-

Table 4. Three tracks for residency \& fellowship education

- General pediatrician

- 3 years of traditional residency

$\circ 1$ year of supervised practice

- Independence

- Advanced skills

- Clinical or clinician-educator subspecialist

- 3 years of traditional residency

$\circ 3$ years of traditional fellowship training

- 1 year of supervised practice as subspecialist

- Independence

- Advanced skills

- Research subspecialist

$\circ 2$ years of traditional residency

$\circ 3$ years of traditional fellowship

- 1 clinical $/ 2$ research

$\circ 2$ years of research with limited supervised practice as subspecialist

- Independence

- Additional research experience (4 years total) 
flected in the statistics from the 2010 PAS meeting, showing attendance by 177 Deans or Department Chairs, 478 Division Chiefs, and 407 Program Directors in pediatrics and across the gamut of pediatric subspecialties (unpublished data).

\section{SUMMARY}

In summary, we need to ask the right question, not what is the correct number of resident duty hours, but rather, how do we train residents. This will involve weighing public concerns and the actual negative consequences of fatigue against insuring sufficient clinical experience for adequately training the next generation of pediatricians, to find the right balance.

\section{REFERENCES}

1. Weiner DL, Manzi SF, Waltzman ML, Morin M, Meginniss A, Fleisher GR 2006 FEMA's organized response with a pediatric subspecialty team: the National Disaster Medical System response: a pediatric perspective. Pediatrics 117(5 Pt 3):S405-11

2. Dr. Richard Friedman. Accepting the risks in creating confident doctors. New York Times, March 17, 2009

3. Blum AB, Raiszadeh F, Shea S, Mermin D, Lurie P, Landrigan CP, Czeisler CA 2010 US public opinion regarding proposed limits on resident physician work hours. BMC Medicine 8:33

4. Dawson R, Reid K 1997 Fatigue, alcohol and performance impairment. Nature 388:235

5. Federal Register 2000;65:25541-25611. http://frwebgate.access.gpo.gov/cgi-bin/ getdoc.cgi?dbname $=2000 \_$register\&docid $=00-10703$-filed

6. Lockley SW, Cronin JW, Evans EE, Cade BE, Lee CJ, Landrigan CP, Rothschild JM, Katz JT, Lilly CM, Stone PH, Aeschbach D, Czeisler CA; Harvard Work Hours, Health and Safety Group 2004 Effect of reducing interns' weekly work hours on sleep and attentional failures. N Engl J Med 351(18):1829-1837
7. Lockley SW, Landrigan CP, Barger LK, Czeisler CA; Harvard Work Hours Health and Safety Group 2006 Aug When policy meets physiology: the challenge of reducing resident work hours. Clin Orthop Relat Res 449:116-27

8. Laine C, Goldman L, Soukup JR, Hayes JG 1993 The impact of a regulation restricting medical house staff working hours on the quality of patient care. JAMA 269(3):374-378

9. Sawyer RG, Tribble CG, Newberg DS, Pruett TL, Minasi JS 1999 Intern call schedules and their relationship to sleep, operating room participation, stress, and satisfaction. Surgery 126:337-42

10. Landrigan CP, Fahrenkopf AM, Lewin D, Sharek PJ, Barger LK, Eisner M, Edwards S, Chiang VW, Wiedermann BL, Sectish TC 2008 Effects of the accreditation council for graduate medical education duty hour limits on sleep, work hours, and safety. Pediatrics 122(2):250-8

11. Jelley MJ 1994 Tools of continuity: the content of inpatient check-out lists. J Gen Int Med 9(Suppl):77

12. Lee LH, Levine JA, Schultz HJ 1996 Utility of a standardized sign-out card for new medical interns. J Gen Int Med 11:753-755

13. Zinn C 199514000 preventable deaths in Australian hospitals. BMJ 310:1487

14. Gottlieb DJ, Parenti CM, Peterson CA, Lofgren RP 1991 Effect of a change in house staff work schedule on resource utilization and patient care. Arch Intern Med 151:2065-70

15. Fletcher KE, Parekh V, Halasyamani L, Kaufman SR, Schapira M, Ertl K, Saint S 2008 Work hour rules and contributors to patient care mistakes: a focus group study with internal medicine residents. J Hosp Med 3(3):228-37

16. Essani R, Scriven RJ, McLarty AJ, Merriam LT, Ahn Hongshik, Bergamaschi R 2009 Simulated laparoscopic sigmoidectomy training: responsiveness of surgery residents. Dis Colon Rectum 52(12):1956-61

17. Hutter MM, Kellogg KC, Ferguson CM, Abbott WM, Warshaw AL 2006 The impact of the 80-hour resident workweek on surgical residents and attending surgeons. Ann Surg 243(6):864-871

18. Cappuccio FP, Bakewell A, Taggart FM, Ward G, Ji C, Sullivan JP, Edmunds M, Pounder R, Landrigan CP, Lockley SW, Peile E on behalf of the Warwick EWTD Working Group 2009 Implementing a 40h EWTD-compliant rota for junior doctors in the UK does not compromise patients' safety: assessor-blind pilot comparison. QJM 102(4):271-82. Epub 2009 Jan 27

19. Moore CL, Copel JA 2011 Point-of-Care Ultrasonography. N Engl J Med $364: 749-57$ 